\title{
System Level Exergy Assessment of Strategies Deployed for SOFC Stack Temperature Regulation and Thermal Gradient Reduction
}

\author{
Shi Tang', Amirpiran Amiri*2, Moses O. Tadé ${ }^{3}$ \\ ${ }^{1}$ Hubei Key Laboratory of Mechanical Transmission and Manufacturing Engineering, Wuhan University of \\ Science and Technology, Wuhan, 430081, PRC \\ ${ }^{2}$ European Bioenergy Research Institute (EBRI), School of Engineering and Applied Science, Aston University, \\ Birmingham, B4 7ET, United Kingdom \\ ${ }^{3}$ Discipline of Chemical Engineering, Curtin University, Kent Street, Bentley, WA 6102, Australia \\ *Corresponding Author: a.p.amiri@ aston.ac.uk
}

\section{Abstract}

Several operational strategies for Solid Oxide Fuel Cell (SOFC) temperature regulation and temperature gradient minimization at cell scale have previously been assessed by the authors (Amiri et al., Ind. Eng. Chem. Res., 2016). The application of such strategies at system scale, however, requires a numerical linkage between the cell and system performance metrics allowing simultaneous evaluation of the dominant process interactions. The objective of this study is to analytically examine the effectiveness and applicability of the mentioned thermal management methods at system scale. To achieve this, a system level exergy analysis is presented by using a modelling platform in which a detailed 4-cell short stack module and the Balance-of-Plant (BoP) are integrated. Linkage between the system performance metrics and the stack internal temperature gradient is specifically emphasized. For this, the exergy intensive points (unit operations) are identified throughout the plant. Subsequently, the effective strategies that had been employed for the cell level thermal management proposed in our previous work (Amiri et al., Ind. Eng. Chem. Res., 2016) are examined at the system level capturing the effects on the state of BoP exergy intensive components. Moreover, fuel design is proposed and evaluated as a potential thermal management strategy. Combination of variety of measures including the exergy destruction rates, the electrical and thermal efficiencies, and the stack internal temperature gradient provides a comprehensive set of data contributing to the SOFC system thermal management.

\section{Introduction}

The role of SOFC technology in addressing the current and future challenges relevant to the world energy demand is crucial. SOFCs offer an efficient and environmentally friendly process to convert chemical energy to electrical energy. The wide spectrum of applications, 
fuel diversity, and high efficiency are typical examples of SOFC technology attractions. However, SOFC system commercialization has been experiencing serious bottlenecks associated with hardware efficiency and durability in addition to sub-optimal operational techniques. In order to fundamentally confront these drawbacks, tremendous efforts have been devoted to this area, at various scales of SOFC system, i.e., micro-, meso-, and macro-scale, by researchers worldwide. ${ }^{1}$ However, the knowledge gaps are still significant demanding further insightful research and development endeavours.

Technical malfunctions such as cell degradation that can cause the unit failure, spare part costs, and reliability risks, are serious challenges that currently decelerate the SOFC commercialization. While fuel cell degradation is mainly attributed to the materials and catalyst physicochemical properties and fuel contaminations, ${ }^{2,3}$ it is also strongly linked to the thermal instability and stress. ${ }^{4,5}$ The latter is particularly important in SOFC case operating at elevated temperatures $\left(700-900^{\circ} \mathrm{C}\right)$ with a high temperature gradients across stack dimensions. Thermal management of SOFC operation is necessary to enhance the stack durability and improve the entire system efficiency leading to an economic viability. Thermal management concept includes not only reduction of thermal stresses inside the SOFC stack by improving thermal homogeneity, but also integration of the heat-sinks and heat-sources throughout the BoP. In this view, thermal management analysis should account for the mentioned aspects at deferent scales targeting sufficient details. To address this, high-fidelity numerical tools that encompass capabilities to capture the multi-scale-multi-physics nature of the fuel cell system are required.

A wide range of thermal analysis modelling studies have been conducted to identify the challenges and opportunities for improving the SOFC performance at cell scale. Previous studies have demonstrated a substantial temperature gradient inside the planar SOFC, typically up to $10 \mathrm{~K} / \mathrm{cm}$ for instance. ${ }^{6,7}$ Minimization of the temperature gradient is of crucial importance to effectively control internal thermal stresses and degradation rate. ${ }^{8}$ Through numerical studies of cell thermal performance it has been proven that both cell design (geometry) and operational factors contribute to temperature gradient. For given SOFC geometry design, the process variables such as operating temperature and voltage, fuel and air flow rates, etc., are typical dominant variables that can be tuned to attain a thermally efficient operation at cell scale. ${ }^{9-12}$ However, the system-wide impacts of the manipulated variables must not be compromised. For instance, while higher air flow rate leads to a lower temperature 
gradient, it can controversially increase the operation cost due to higher blower power and sizing issues. Riensche et al. ${ }^{13}$ have shown that the plant-wide operation cost can reduce by $20 \%$ by allowing higher temperature increase across the cell, $150 \mathrm{~K}$ instead of $100 \mathrm{~K}$. Authors have previously investigated the operating strategies that result in efficient control of thermal inhomogeneity inside SOFC without causing major efficiency/cost consequences. ${ }^{14}$ In the mentioned work three operational variations, including the surplus air flowrates, the input gases temperature difference, and the oxygen concentration in cathode gases, have been proposed and extensively analyzed to demonstrate their impacts of temperature gradient reduction. However, these operating approaches must be assessed at the system level where a shortcoming exists in terms of understanding the interaction between system efficiency and stack function homogeneity, performance loss mechanisms, and overpotentials, etc. At the system/plant scale the optimum energy generation and utilization are commonly targeted. In this view, exergy analysis is a technically informative approach for evaluation and optimization of plant convertible energy and energy losses. For a complex thermodynamic system, the exergy analysis allows for the local energy destruction calculations associated with the sub-processes in the system that are necessary information needed for entire plant optimization. ${ }^{15-17}$

The SOFC efficiency maximization based on the exergy evaluation has been investigated in the literature without considering the BoP compartments influences. ${ }^{18}$ Compared to the isolated SOFC cell performance, the electrochemical behaviour of SOFC stack embedded in a system can be different and more complicated due to the BoP units interactions, indicating the importance of system features that have not sufficiently been studied in the mentioned literature. Various SOFC plant flowsheets, including different co-generation plants, have been considered to demonstrate the system configuration as a promising option for system efficiency enhancement. ${ }^{19-21}$ Additionally, efficiency improvement via operating parameters tuning, such as anode off-gas recycle ratio, and operation strategies, such as internal reforming, etc., have been studied ${ }^{19,22-26}$ using exergy concept. The drawback in these studies is the stack details that have been ignored or simplified while deployment of the proposed methods may affect the stack operation uniformity and stability. ${ }^{27}$ Calise et al. ${ }^{26}$ conducted an exergy analysis for a SOFC plant, considering variables distributions in the stacking direction of a tubular SOFC, while it cannot represent the planar SOFC behaviour due to geometry and the distributed variables differences. Accordingly, this work - compared to the literature as shown in Table 1 - presents a state-of-the-art contribution to the SOFC stack and system thermal management 
using a plant scale exergy analysis. This study illustrates the mutual interaction between the stack and system performances. The investigation demonstrates the extent to which various operational strategies can be effective to improve the stack thermal performance and system exergy dissipation.

Table 1: Comparison of a number of recent SOFC exergy studies.

\section{SOFC system simulation platform}

The process exergy analysis highly relies on the plant data including streams mass and energy data and mixtures physicochemical properties. A SOFC simulation platform developed by authors ${ }^{28,29}$ was used in this work to achieve the mentioned raw data. The simulator has already been validated against a real-life SOFC system rig approving its capability of a multi-scale performances capturing of the SOFC system. ${ }^{30}$ The platform capability and fidelity for estimating the BoP mass and energy balances and the stack internal profiles have been demonstrated and validated in our previous research. ${ }^{29}$ The simulated process flowsheet was selected to be rather comprehensive encompassing the main sub-processes of a SOFC plant including fuel conditioning, power generation through electrochemical process, depleted-fuel combustion and the heat recovery units that are the most likely elements of the system for the commercialization in short-term $^{31}$. The analysis outcome relevant to each operation units may be generalized when the process configuration changes. This is because the fundamental equations used still apply, in spite of change in unit location and inputs. Therefore, the presented modelling framework is capable enough to be used for various fuel cell system layouts.

\section{Energy and exergy analysis fundamentals}

Given the process flowsheet data, the energy and exergy analysis for SOFC system were carried out based on the fundamental equations as follows. Energy for each stream was calculated based on the enthalpy correlation (Equation 1).

$$
E=\sum \dot{m} C_{p}\left(T-T_{0}\right)
$$

The net electrical efficiency of system based on energy analysis was calculated as by using Equation 2:32

$\eta_{e l}^{e n}=\frac{P_{\text {net }}}{(\dot{m} \cdot L H V)_{\text {fuel }}}$ 
1 While the fresh air blower is the main power consumption module in the system due partly to

2 the high air-to-fuel flowrate ratio and long fluid flow line downstream, the anode off-gas recycle

3 line pressure drop might be effective on the overall system performance. The pressure drop in

4 recycle line may typically be $\sim 80$ mbar. ${ }^{19}$ The simulation platform allows the pressure drop

5 consideration in individual components throughout the plant. Since hydrodynamics calculations

6 were out of this work scope, the units' pressure drops were assumed to be constant values

7 published in literature. ${ }^{19,33}$ An anode recycle blower was considered to compensate the anode

8 recycle line pressure drop, as shown in the process flow diagram, Figure 1. The blower duty

9 would be estimated by simulator based on the total pressure drop in the, pre-reformer and stack anode channels. The relevant power consumption term appears in Equation 3 slightly affecting performance metrics. The isentropic efficiency for the blowers was assumed to be $60 \% .{ }^{34}$

$P_{n e t}=(U I)_{s t a c k}-P_{b l}^{a i r}-P_{b l}^{\text {recycle }}$

For the SOFC system in this study, the high grade exhaust gas temperature was around $400 \mathrm{~K}$ that could be utilised for heating purposes. ${ }^{35}$ For evaluation of available thermal energy $\left(\mathrm{E}_{\mathrm{th}}\right)$ in the system, the enthalpy of the system exhaust gas was calculated. The portion of the exhaust heat that can be recovered can vary from $\sim 38 \%$ to $\sim 70 \%$ depending on the recovery process type and design. ${ }^{19,36,37}$ For comparison purpose the heat recovery ratio, $\varepsilon$, was assumed to be $60 \%$ in the current work. Accordingly, the thermal efficiency of the system can be estimated using Equation 5:

$20 \quad \eta_{t h}^{e n}=\frac{\varepsilon E_{t h}}{(\dot{m} \cdot L H V)_{f u e l, i n}}=\frac{\varepsilon E_{e f}}{(\dot{m} \cdot L H V)_{f u e l, i n}}$

21 For the exergy analysis, the exergy for each material stream was estimated based on the physical $\left(\mathrm{Ex}^{\mathrm{ph}}\right)$ and chemical $\left(\mathrm{Ex}^{\mathrm{ch}}\right)$ exergies: ${ }^{23}$

$(E x)_{m}=E x^{c h}+E x^{p h}$

24 Chemical exergy of a material stream can be calculated by using Equation $7:^{18,23}$

$E x^{c h}=\sum_{i} \dot{m}_{i} E x_{i}^{0}+R T_{0} \sum_{i} \dot{m}_{i} \ln \left(\mathrm{y}_{\mathrm{i}}\right)$

26 Streams physical exergy can be estimated through Equation $8:^{23}$

27

$E x^{p h}=\dot{m}\left[\left(h-h_{0}\right)-T_{0}\left(s-s_{0}\right)\right]$ 
1 Exergy-based thermal and electrical efficiencies can be calculated using Equation 9 and 10,

2 respectively. The thermal exergy was estimated as recoverable portion of the effluent stream

3 physical exergy.

$4 \quad \eta_{e l}^{e x}=\frac{P_{n e t}}{E x_{i n}}$

$5 \quad \eta_{t h}^{e x}=\frac{\varepsilon E x_{t h}}{E x_{i n}}=\frac{\varepsilon E x_{e f}^{p h}}{E x_{i n}}$

6 Accordingly, the total efficiency with respect to exergy is,

$7 \quad \eta_{\text {total }}^{e x}=\frac{P_{n e t}+\varepsilon E x_{t h}}{E x_{i n}}$

8 The destroyed exergy or irreversibility associated with an individual process was calculated 9 based on the input/output exergy of the material stream, heat stream and power for the process: ${ }^{23}$

$\mathrm{Ex}_{\text {ir }}=\sum_{\text {in }}(E x)_{m}-\sum_{\text {out }}(E x)_{m}+\sum_{\text {in }}(E x)_{h}-\sum_{\text {out }}(E x)_{h}-\sum(E x)_{P}$

$12(E x)_{h}=\left(1-\frac{T_{0}}{T}\right) Q$

in which, exergy of material streams, $(E x)_{m}$, was calculated based on Equation 6, 7 and 8; exergy of heat streams, $(\mathrm{Ex})_{\mathrm{h}}$, was estimated based on Equation 13, where Q is the available heat energy at temperature T; power exergy, $(E x)_{\mathrm{P}}$, equals to the power itself.

Accordingly the destroyed-to-input exergies ratio can be calculated as:

$17 \quad \mu_{i r}^{e x}=\frac{E x_{i r}}{E x_{i n}}$

\section{Results and discussions}

\section{Exergy intensive units}

23 The local irreversibility in process compartments/units, alternatively known as exergy 24 destruction associated with individual BoP elements, was firstly calculated. For this target, plant 25 simulation results were used in the exergy correlations. This allows shortlisting the exergy26 intensive points of process that must be specifically focused on during the assessment of the 
cooling strategies. The process flowsheet and simulation inputs are shown in Figure 1 and Table 2 , respectively. The process flow diagram is a generic one that consists of major BoP units such as gas blower, heat exchangers fuel burners, external reformer, etc. Since this paper aims at a plant-wide exergy analysis, the system flowsheet was selected in the way that involves the major BoP components that might be the bottlenecks in terms of exergy destruction. In all of the simulation cases in this paper the external fuel processing was considered ensuring less than $0.5 \%$ (molar) of methane in reformer exhaust stream, fed into SOFC stack. Therefore, the internal reformation was negligible.

Figure 1: Process layout for a SOFC system showing the indicative exergy results for the basis case (BC) simulation including the sub-process exergy loss (rectangular boxes with arrow), exergy loss to the input exergy into the system ratio (oval boxes), and system input and output exergies (rectangular boxes without arrow).

Table 2: The model parameters for the electrochemical simulation of the SOFC stack and system (BC).

Shares of system energy/exergy elements are depicted in Figure 2. The electrical output percentage is associated with energy analysis is higher than that in exergy analysis. The value of input fuel exergy is higher than the energy input estimated based on the LHV while generated electricity is the same in both cases. The system recoverable and wasted heat estimated through exergy- and energy-based analyses show substantial differences. This is mainly because of destroyed exergy considerations. Figure 2 indicates how share values may alter using either energy or exergy concepts as the assessment basis. The conversion of energy is evaluated in the energy analysis, according to the first law of thermodynamics. For this study, electrical power and heat waste construct the input energy. While in the exergy analysis, based on second law of thermodynamics, a portion of the energy is destroyed and cannot be converted to the work (irreversibility), leading to the entropy increase in the process, 
Figure 2: The plant analysis based on the energy and exergy principles.

\section{$4 \quad$ Parameter studies of thermal behavior}

5 The process features at the stack and system scales were integrated. In this view, process characteristics measures including the stack temperature gradient, system efficiency, individual efficiency terms, and irreversibility values were estimated examining the promising thermal-effective scenarios. Four operational strategies including the utilization of surplus air, deployment of oxygen-enriched air, manipulation of anode exhaust recycling rate, and variation of fuel source were assessed. For all case studies, the various fuels and air with proper qualities, were assumed to be ready to be fed into the system. The gases production processes such as oxygen enrichment process, gasification, etc., were not considered. The exergy of system material streams were estimated based on Equation 5-7.

\section{Case 1: Utilization of surplus air}

The SOFC cathode is supplied with air to exploit its cooling potential and as the oxygen supply for quintessential electrochemical reaction. It is widely acknowledged that regulation of the temperature rise and the thermal gradient inside the SOFC stack can be achieved and maintained by the utilisation of an optimized flow of excess air. Careful optimisation must be conducted by considering the necessary trade-off between the mentioned advantages and the disadvantages relevant to sizing and parasitic losses. The impact of excess air deployment on system efficiency terms (thermal and electrical), total efficiency, and exergy losses have been estimated. A sensitivity analysis has been carried out for the system operating with the air flowrate ranging from $50 \%$ to $200 \%$ of $\dot{m}_{\text {basis }}^{\text {air }}$ where $\dot{m}_{\text {basis }}^{\text {air }}$ is the air mass flowrate of base simulation. For the sake of viability, the manipulating range was chosen to be consistent with the practical excess air ratios reported in literature. ${ }^{19,38-39}$ The fuel flowrate was kept consistently unchanged in all studied cases. The impacts on the system and stack performance metrics are presented in Table 3. In addition, effects on the exergy losses at various parts of the BoP are presented in Figure 2. 
1 are strongly affected by the air flowrate applied to the system. Temperature uniformity has been remarkably enhanced at higher airflows. The observed results are in agreement with the previous research outcomes. ${ }^{9}, 40$ The outcomes are particularly of technical importance to minimize thermal stresses and also achieve homogenous reaction profiles inside stack. At the system scale, however, the negative consequences are markedly worrying; further restraining the deployment of this strategy. For instance, for the air flow ratio varying from 0.5 to 2.0 in a system operating at a constant voltage, the electrical efficiency experiences significant reduction, approximately $7.2 \%$; due to the interactive cooling effect $(\sim 104 \mathrm{~K})$ and the electrochemical reaction rate that result in current generation drop. Moreover the higher air flow, the high air blower power consumption would be imposed on the system reducing $\mathrm{P}_{\text {net }}$. Furthermore, thermal efficiency declines by $4.8 \%$. In this view, the electrical efficiency is seen to be more sacrificed by deployment of surplus air, compared to thermal efficiency. Principally, the share of electrical efficiency in achievable total efficiency is dominant. In the best case the thermal efficiency can improve the overall efficiencies by $7.6 \%$; in this particular case study. The total exergy efficiency is reduced by $12.0 \%$ due to the reduction in both current generation and increased exergy losses. The part of fuel exergy that was not harnessed as electrical power could not be gained as thermal energy, as the exergy losses values show.

The influence of exploiting surplus air on exergy intensive units is presented in Figure 3. As can be seen in this figure, the exergy loss growth with excess air for exergy intensive units, the total loss is mainly dominated by the boosted exergy dissipation in the air preheater due to higher air flowrates. A similar, but moderated, behavior was observed in other equipment such as, the after burner, fuel preheater, etc. In these units since temperature differences are much lower in contrast to temperature change in the air heater, lower exergy losses are observed.

Figure 3: Ratio of the exergy losses to the total exergy input for different air flow rates.

\section{Case 2: Utilisation of oxygen-enriched air}

The higher partial pressure of oxygen in the cathode gas can enhance the stack electrical efficiency. The rational reason that explains this is the improved electrochemical reaction, Nernst voltage and the reduced overpotentials. ${ }^{20,41}$ Grounded on this, it has been shown in our previous work ${ }^{14}$ that utilization of oxygen-enriched air, instead of natural air may, to some 
extent, compensate the negative consequences caused by surplus air exploitation in the SOFC stack for cooling. However, since air treatment imposes extra process costs, the process economics has also been assessed in ${ }^{14}$ to figure out the practical margins. As the last but not the least step, feasibility study at plant level was conducted in this work.

A range of oxygen concentrations in the cathode air were examined. The performance metrics for the entire system and individual plant components were calculated as presented in Table 4 and Figure 4 . The overall system efficiency shows $1.7 \%$ growth by doubling the air oxygen quality. This is due to the electrical performance enhancement up to $2.7 \%$. However, the thermal efficiency and the temperature distribution smoothness are negatively affected. Since fuel utilization is increased along with the higher current generation according to Faraday's Law the enhancement of the electrical performance leads to the lesser amount of unreacted fuel remained in the anode exhaust that consequently generates lower combustion heat in the burner. Accordingly the exhaust temperature drops causing heat quality reduction. Note that the overall irreversibility slightly drops, about $1.5 \%$, with the oxygen quality as shown in Table 4. The detailed exergy results associated with the exergy-intensive units reveals that the irreversibility improvement is mainly attributed to the burner unit due to the lower amount of fuel being combusted compared to the BC. Furthermore, taking the air pre-heater module into account, since the process stream (air) flowrate and temperature growth are kept the same in all of the case studies, the minor variation of exergy loss in this unit is because of the hot stream physicochemical properties variation such as its heat capacity as function of the gas mixture composition.

Table 4: Simulation results for the system and stack behavior deploying various oxygen concentration in cathode.

Figure 4: Ratio of the exergy losses to the total exergy input for different oxygen concentrations used in cathode gas.

\section{Case 3: Anode off-gas recycle}

Anode off-gas recycle stream in the BoP is to increase the stack efficiency through improving the fuel utilization and the heat and water recovery. ${ }^{19,}{ }^{42}$ Even though the maximum overall (system) fuel utilization is a sought-after target, the single-pass fuel utilization must be kept limited within a safe margin to control the concentration loss and fuel starvation inside cells. Optimization of the anode recycle ratio (ARR) allows to chive this target. The impact of ARR 
1 variations on BoP exergy dissipation and the stack internal profiles must be considered as crucial constraints or even objectives in defining the ARR optimization problem.

3

The estimated results for both system and stack performance against ARR alteration are presented in Table 5. Moreover, Figure 5 depicts the process compartments exergy losses versus ARR. It can be seen that while higher ARR improves the system efficiency, it may lead to a higher degree of thermal inhomogeneity inside the stack. Even though a stack with complete external fuel reformation is considered in this study, it reasonably compares with the results achieved by Nikooyeh et. al. ${ }^{43}$ for internal fuel reformation.

The modelling results presented in Table 5 demonstrates the substantial negative effect of ARR on the interior temperature distribution increasing thermal gradient by $\sim 30 \%$ for ARR ranging from 0.1 to 0.7 . In contrast, the electrical efficiency improves with the anode ARR owing to the electrochemical reaction enhancement. With variation of ARR from 0.1 to 0.7 , electrical efficiency is improved up to $5.4 \%$ while thermal efficiency slightly reduces that is mainly contributed to the lower amount of unreacted fuel left that results in lower heat grade at the burner exhaust.

A reduction in irreversibility ratio, about 3.5\%, is also observed for whole ranges of the ARR in Table 5. The individual exergy behaviours versus the ARR are shown in Figure 5. While burner exergy is highly sensitive to the ARR variations, its effect on the air preheater and other BoP components is minor. This is because at higher fuel utilization at higher ARR, lowering the unreacted fuel flow fed to burner. Furthermore, the anode exhaust temperature is risen, moderating the temperature difference between the burner inlet and outlet. The lower temperature difference and lower fuel flow, explains the declining burner exergy loss. Other BoP compartments exergy loss increased with the ARR. This can be mainly ascribed to the increased flowrate of the recycling stream passing through the anode mixer and pre-reformer. The controversial behaviour captured for the system performance metrics and the stack thermal inhomogeneity requires a trade-off between system efficiency and durability. 
Figure 5: Effect of ARR on BoP units' exergy loss ratio.

\section{Case 4: Fuel variation}

6 Since SOFC has capability to be fuelled with various fuels, fuel design might provide 7 potentials to minimize the internal gradients while system electrical and thermal requirements are met. Process analysis was furthered to examine different fuels in the operation, monitoring the system performance and stack thermal measures. The so-called "Designed Fuel" is syngas mixed with the basis fuel (Table 2 and 6). All of the studied fuel sources are shown in Table 6. The syngas composition used in this study was given in literature ${ }^{44}$. It is actually a coalderived syngas $(\mathrm{LHV}=217.24 \mathrm{~kJ} / \mathrm{mol})$ and is assumed to be available to be fed into the system. Accordingly, the only fuel processing for such a feed is the WGR. For the methane rich case $(\mathrm{BC}, \mathrm{LHV}=724.13 \mathrm{~kJ} / \mathrm{mol})$ both SR and WGR occur and reformate (stack feed) composition is very different compared to reformate achieved in syngas case. SR, due to its endothermic nature, enables to recover the exhaust heat as electricity, and hence reducing the destroyed exergy, which is not that possible in the syngas-fed system. For the sake of consistency fuel flow ratios were adjusted to ensure the same exergy input in all cases. As can be seen in Table 6 , a significant electrical efficiency reduction of $\sim 29.9 \%$ is observed for the syngas fraction varying from 0 to 1 , while smoother thermal profiles are achievable. The hydrogen quality in a syngas enriched fuel is lower than basis fuel. Moreover, average operating temperature lowered due to higher gas flow and also reduced heat released from electrochemical reaction. All of these, result in the reduced current generation and electrical efficiency. The key point is that the total exergy efficiency experiences $15.2 \%$ reduction that is explainable via thermal efficiency improvement.

Table 6: Simulation results for the system thermal behaviour operating on different fuels.

The individual loss variations in BoP elements against fuel composition are illustrated in Figure 6. In contrast to Case 1, the higher fuel flowrate of simulated fuels, required to ensure the equal input exergy, does not cause an outstanding irreversibility growth, being only around $5.1 \%$. The exergy loss is because of the increase in entropy that is a function of gas flowrate 
and its temperature change. The exergy loss in air heater increased slightly with the increase of syngas fraction. This would be the results under both effects of lower temperature differences for the heat exchanging process caused by the decreased stack exhausts temperature, and also the increase of the fuel flowrate. The exergy loss in the after burner increases slightly as well, this could attribute to both the higher content of the un-reacted fuel in stack anode exhaust and the increase of fuel flowrates.

The exergy dissipation for pre-reforming process, including fuel preheating and reformation, declines with the syngas fraction. This is due to the exothermic nature of the syngas reforming reaction, increasing the reformate temperature that subsequently leads to a lower heating duty. In this case, therefore, the reduction of irreversibility due to the exothermic reaction makes up the irreversibility generated by flowrates, saving exergy, in comparison to Case 1.

This is of interest in the systems in which thermal-to-electrical performance must be balanced such as SOFC system used for residential applications. Syngas, in contrast to the BC, sounds promising for achieving thermal smoothness and higher thermal-to-electrical performance ratio. Note that syngas from sources rather than natural gas, such as biomass gasification, may include higher contaminants. The impact of fuel contaminants on SOFC degradation is out of scope of this study. For assessing the SOFC lifetime improvement, one should consider both thermal malfunctions/damages and contaminant relevant degradation.

Figure 6: Ratio of the exergy loss to the total exergy input for different fuel compositions used in the system.

\section{Optimization strategy}

For a system fed by a fixed fuel (the BC), the system efficiency variation against $\Delta \mathrm{T}_{\mathrm{x}}$ for individual strategies is presented in Figure 7. The simultaneous evaluation of stack thermal behavior and system efficiency reveals that there are two operation regions including the system efficiency improvement region and the stack thermal improvement region. Each region offers specific possibilities for trade-off between the stack and system design and operation.

Figure 7: System efficiency against the stack temperature gradient for individual operational strategies. 
1 Taking the limitation of the technically feasible ranges for each variable into account, the 2 scope of surplus air application was the widest among the studied approaches. Moreover, in 3 the stack thermal improvement region the surplus air application was observed to be more 4 effective approach for the temperature gradient improvement offering less negative influence 5 on the system efficiency compared to the ARR reduction method. It, however, affects the

Figure 8: System exergy-based efficiency again the stack thermal gradient for coolant air flowrates varying from 0.5 to 2 times of the basis air flow, combined with ARR and yo2 impact.

\section{Conclusion}

In spite of the substantial progress in fuel cell technology in the last two decades, its lifetime is yet to be improved to address the commercialization requirements. In order to deal with this challenge, operational techniques that result in thermally homogenous SOFC performance is of high importance. In this paper, as a scaled-up modelling study, the SOFC stack thermal homogeneity and system exergy were simultaneously evaluated. The focus was on the investigation of four different cases including the utilization of surplus air, deployment of oxygen-enriched air, manipulation of anode exhaust recycling rate, and variation of fuel source. The main outcomes of this study are as follows: 
- Application of surplus air is highly effective for temperature adjustment and thermal uniformity on the cost of thermal and electrical efficiencies reduction and also increase in exergy destruction in all of BoP compartments, the air pre-heater in particular. In spite of the higher stack efficiency at smoother temperature profile, the system overall efficiency shows the reduction that demonstrates the critical role of the exergy losses. The optimized excess air flow should be achieved through a multi-objective optimization that compromises the stack thermal homogeneity and the overall system efficiency.

- Utilization of oxygen-enriched air was considered to see if it can compensate for a portion of the efficiency sacrificed by using surplus normal air. The results indicated that electric and thermal efficiencies increases and decreases, respectively when oxygen enriched air is used. However the total improvement in net efficiency in less than 3\% by doubling oxygen fraction in the used air.

- It is observed that the thermal gradient is negatively affected by higher ARR while it is positively effective for efficiency improvement and water management in the SOFC system.

- Fuel composition adjustment is shown to be a potential methodology to successfully balance thermal homogeneity and system efficiency. Moreover it has been observed that this method can be used to balance the thermal and electrical efficiencies that is compatible for the application of interest.

- While the trade-off between system electrical efficiency and homogeneity of stack operation is usually essential, the modelling results show that simultaneous enhancement in stack internal profiles and system thermal efficiency is feasible.

\section{Acknowledgements}

The authors acknowledge the financial supports by Hubei Provincial Natural Science Foundation of China (Grant No. 2018CFB143) for this research. 


\section{Nomenclature}

$2 \mathrm{C}_{\mathrm{p}}$

$3 \mathrm{E}$

4 Ex

$5 \mathrm{Ex}^{0}$

6 F

$7 \mathrm{~h}$

8 I

9 LHV

$10 \dot{\mathrm{m}}$

$11 \mathrm{~N}_{\mathrm{e}}$

$12 \mathrm{P}$

$13 \quad P_{\text {in }}$ System

$14 \quad \mathrm{P}_{\text {net }}$

$15 \quad \mathrm{P}_{\mathrm{bl}}$

$16 \mathrm{Q}$

$17 \mathrm{R}$

$18 \mathrm{~s}$

$19 \mathrm{~T}$

$20 \quad \overline{\mathrm{T}}$

$21 \Delta \mathrm{T}_{\mathrm{x}}$

$22 \mathrm{U}$

$23 \mathrm{y}$

24 Greek Letters

$25 \gamma$

$26 \varepsilon$

$27 \quad \eta$

$28 \mu$

29 Sub-/Superscripts

30 blower

$31 \mathrm{ch}$

32 el

33 en

34 ex

35 ef

$36 \mathrm{~h}$

$37 \quad \mathrm{i}$

38 in

39 ir
Specific heat $\left(\mathrm{J} \mathrm{mol}^{-1} \mathrm{~K}^{-1}\right)$

Energy (W)

Exergy (W)

Standard chemical exergy $\left(\mathrm{J} \mathrm{mol}^{-1}\right)$

Faraday's constant $\left(96,485 \mathrm{C} \mathrm{mol}^{-1}\right)$

Enthalpy $\left(\mathrm{J} \mathrm{mol}^{-1}\right)$

Current (A)

Lower heating value $\left(\mathrm{J} \mathrm{mol}^{-1}\right)$

Molar flow rate $\left(\mathrm{mol} \mathrm{s}^{-1}\right)$

Number of electrons

Pressure $(\mathrm{Pa})$

System input power (W)

Net power (W)

Blower power (W)

Heat energy (W)

Ideal gas constant $\left(=8.314 \mathrm{~J} \mathrm{~mol}^{-1} \mathrm{~K}^{-1}\right)$

Entropy $\left(\mathrm{J} \mathrm{mol}^{-1} \mathrm{~K}^{-1}\right)$

Temperature (K)

Average temperature (K)

Temperature gradient $\left(\mathrm{K} \mathrm{mm}^{-1}\right)$

Cell voltage (V)

Molar fraction

Specific heating ratio $(=1.4$ from [30])

Heat recovery coefficient

Efficiency (\%)

Destroyed-to-input exergies ratio

Air blower

Chemical

Electrical

Energy

Exergy

Effluent

Heat stream

Species

Inlet

Irreversibility 


$\begin{array}{rlll}1 & \text { insen } & \text { Isentropical } \\ 2 & \mathrm{~m} & \text { Material stream } \\ 3 & \text { out } & \text { Outlet } \\ 4 & \mathrm{P} & \text { Power } \\ 5 & \text { ph } & \text { Physical } \\ 6 & \text { stack } & \text { SOFC stack } \\ 7 & \text { th } & \text { Thermal } \\ 8 & 0 & \text { Reference condition }\left(\mathrm{T}_{0}=298 \mathrm{~K}, \mathrm{P}_{0}=1.013 \text { bar }\right) \\ 9 & \text { Acronyms } & \\ 10 & \text { ARR } & \\ 11 & \text { BC } & \text { Anode recycle ratio } \\ 12 & \text { BoP } & \text { Basis case } \\ 13 & \text { DF } & \text { Balance of Plant } \\ 14 & \text { SOFC } & \text { Designed fuel } \\ & & \text { Solid oxide fuel cell }\end{array}$

\section{References}

17 (1) Behling, N. H., Fuel Cells: Current Technology Challenges and Future Research Needs; Elsevier 18 Science Ltd: New York, 2012.

19 (2) Lanzini, A.; Ferrero, D.; Papurello, D.; Santarelli, M., Reporting Degradation from Different Fuel 20 Contaminants in Ni- anode SOFCs. Fuel Cells. 2017.

(3) Tjønnås, J.; Zenith, F.; Halvorsen, I. J.; Klages, M.; Scholta, J., Control of Reversible Degradation Mechanisms in Fuel Cells: Mitigation of CO contamination. IFAC-Papers On Line 2016, 49, 302.

(4) Pianko-Oprych, P.; Zinko, T.; Jaworski, Z., A Numerical Investigation of the Thermal Stresses of a 24 Planar Solid Oxide Fuel Cell. Mater. 2016, 9.

(5) Min, X.; Li, T.; Ming, Y.; Martin, A., Solid oxide fuel cell interconnect design optimization considering the thermal stresses. Sci. Bull. 2016, 61, 1333.

(6) Recknagle, K. P.; Williford, R. E.; Chick, L. A.; Rector, D. R.; Khaleel, M. A., Three-dimensional thermo-fluid electrochemical modeling of planar SOFC stacks. J. Power Sources. 2003, 113, 109.

(7) Yakabe, H.; Ogiwara, T.; Hishinuma, M.; Yasuda, I., 3-D model calculation for planar SOFC. $J$. Power Source.s 2001, 102, 144.

(8) Chiang, L. K.; Liu, H. C.; Shiu, Y. H.; Lee, C. H.; Lee, R. Y., Thermo-electrochemical and thermal stress analysis for an anode-supported SOFC cell. Renewable Energy 2008, 33, 2580.

(9) Yang, Y.; Wang, G.; Zhang, H.; Xia, W., Computational analysis of thermo-fluid and electrochemical characteristics of MOLB-type SOFC stacks. J. Power Sources 2007, 173, 233.

(10) Huang, C. M.; Shy, S. S.; Lee, C. H., On flow uniformity in various interconnects and its influence to cell performance of planar SOFC. J. Power Sources 2008, 183, 205.

(11) Grondin, D.; Deseure, J.; Zahid, M.; Garcia, M. J.; Bultel, Y., Optimization of SOFC interconnect design using Multiphysic computation. In Computer Aided Chemical Engineering Series 25; Bertrand, 
(12) Wang, Y.; Yu, J.; Cao, X., Numerical analysis of optimal performance of planar electrode supported solid oxide fuel cell at various syngas flow rates. Energy Convers. Manage. 2014, 77, 637.

3 (13) Riensche, E.; Stimming, U.; Unverzagt, G., Optimization of a $200 \mathrm{~kW}$ SOFC cogeneration power 4 plant: Part I: Variation of process parameters. J.Power Sources 1998, 73, 251.

5 (14) Amiri, A.; Tang, S.; Vijay, P.; Tadé, M. O., Planar Solid Oxide Fuel Cell Modeling and 6 Optimization Targeting the Stack's Temperature Gradient Minimization. Ind. Eng. Chem. Res. 2016, $755,7446$.

8 (15) Kumar, R., A critical review on energy, exergy, exergoeconomic and economic (4-E) analysis of 9 thermal power plants. JESTECH. 2016, 20.

(16) Rosen, M. A.; Dincer, I., Exergy as the confluence of energy, environment and sustainable development. Exergy Int. J. 2001, 1, 3.

(17) Utlu, Z.; Hepbasli, A., A review on analyzing and evaluating the energy utilization efficiency of countries. Renew. Sust. Energ. Rev. 2007, 11, 1.

(18) Wongchanapai, S.; Iwai, H.; Saito, M.; Yoshida, H., Selection of suitable operating conditions for planar anode-supported direct-internal-reforming solid-oxide fuel cell. J. Power Sources 2012, 204, 14.

(19) Braun, R. J.; Klein, S. A.; Reindl, D. T., Evaluation of system configurations for solid oxide fuel cell-based micro-combined heat and power generators in residential applications. J. Power Sources 2006, 158, 1290.

(20) Duan, L.; Zhang, X.; Yang, Y., Exergy Analysis of a Novel SOFC Hybrid System with Zero-CO2 Emission. InTech. 2011, 27.

(21) Bang-Møller, C.; Rokni, M.; Elmegaard, B., Exergy analysis and optimization of a biomass gasification, solid oxide fuel cell and micro gas turbine hybrid system. Energy 2011, 4740.

(22) Stamatis, A.; Vinni, C.; Bakalis, D.; Tzorbatzoglou, F.; Tsiakaras, P., Exergy Analysis of an Intermediate Temperature Solid Oxide Fuel Cell-Gas Turbine Hybrid System Fed with Ethanol. Energies 2012, 5, 4268.

(23) Fryda, L.; Panopoulos, K. D.; Karl, J.; Kakaras, E., Exergetic analysis of solid oxide fuel cell and biomass gasification integration with heat pipes. Energy 2008, 33, 292.

(24) Akkaya, A. V.; Sahin, B.; Huseyin Erdem, H., Exergetic performance coefficient analysis of a simple fuel cell system. Int. J. Hydrogen Energy 2007, 32, 4600.

(25) Hotz, N.; Senn, S. M.; Poulikakos, D., Exergy analysis of a solid oxide fuel cell micropowerplant. J. Power Sources 2006, 158, 333.

(26) Calise, F.; Ferruzzi, G.; Vanoli, L., Parametric exergy analysis of a tubular Solid Oxide Fuel Cell (SOFC) stack through finite-volume model. Appl. Energy 2009, 86, 2401.

(27) Yang, S., Improving a Solid oxide fuel cell system through exergy analysis Int. J. Exergy 2016, 21.

(28) Amiri, A.; Vijay, P.; Tadé, M. O.; Ahmed, K.; Ingram, G. D.; Pareek, V.; Utikar, R., Solid oxide fuel cell reactor analysis and optimisation through a novel multi-scale modelling strategy. Comput. Chem. Eng. 2015, 78, 10.

(29) Amiri, A.; Vijay, P.; Tadé, M. O.; Ahmed, K.; Ingram, G. D.; Pareek, V.; Utikar, R., Planar SOFC system modelling and simulation including a 3D stack module. Int. J. Hydrogen Energy 2016, 41, 2919.

(30) Amiri, A.; Tang, S.; Steinberger-Wilckens, R.; Tadé, M. O., Evaluation of fuel diversity in Solid Oxide Fuel Cell system. Int. J. Hydrogen Energy 2018. 
(31) Ii, T. A. A.; Nease, J.; Tucker, D.; Barton, P. I., Energy Conversion with Solid Oxide Fuel Cell Systems: A Review of Concepts and Outlooks for the Short- and Long-Term. Ind. Eng. Chem. Res. 2013, 52, 3089.

(32) Lin, Z.; Xi, L.; Jiang, J.; Li, S.; Jie, Y.; Jian, L., Dynamic modeling and analysis of a 5-kW solid oxide fuel cell system from the perspectives of cooperative control of thermal safety and high efficiency. Int. J. Hydrogen Energy 2015, 40, 456.

(33) Liso, V.; Olesen, A. C.; Nielsen, M. P.; Kær, S. K., Performance comparison between partial oxidation and methane steam reforming processes for solid oxide fuel cell (SOFC) micro combined heat and power (CHP) system. Energy 2011, 36, 4216.

(34) Peters, R.; Deja, R.; Blum, L.; Pennanen, J.; Kiviaho, J.; Hakala, T., Analysis of solid oxide fuel cell system concepts with anode recycling. International J. Hydrogen Energy 2013, 38, 6809.

(35) Bedringås, K. W.; Ertesvåg, I. S.; Byggstøyl, S.; Magnussen, B. F., Exergy analysis of solid-oxide fuel-cell (SOFC) systems. Energy 1997, 22, 403.

(36) Nehrir, M.; Wang, C., Modeling and Control of Fuel Cells:Distributed Generation Applications; Wiley-IEEE Press: Piscataway2009.

(37) Iv, E. J. N.; Sleiti, A. K., Potential of SOFC CHP systems for energy-efficient commercial buildings. Energy \& Buildings 2013, 61, 153.

(38) Pirkandi, J.; Ghassemi, M.; Hamedi, M. H.; Mohammadi, R., Electrochemical and thermodynamic modeling of a CHP system using tubular solid oxide fuel cell (SOFC-CHP). J. Cleaner Prod. 2012, 29, 151.

(39) Jiang, J.; Li, X.; Li, J., Modeling and Model-based Analysis of a Solid Oxide Fuel Cell ThermalElectrical Management System with an Air Bypass Valve. Electrochim. Acta 2015, 177, 250.

(40) Janardhanan, V. M.; Heuveline, V.; Deutschmann, O., Performance analysis of a SOFC under direct internal reforming conditions. J. Power Sources 2007, 172, 296.

(41) Kaur, G. Solid oxide fuel cell components: Interfacial compatibility of SOFC glass seals; Springer International Publishing: Switzerland, 2015.

(42) Bejan, A., Tsatsaronis, G., and Moran, M. Thermal design and optimization; John Wiley Sons Inc.: New York 1996.

(43) Nikooyeh, K.; Jeje, A. A.; Hill, J. M., 3D modeling of anode-supported planar SOFC with internal reforming of methane. J. Power Sources 2007, 171, 601.

(44) Yi, Y.; Rao, A. D.; Brouwer, J.; Samuelsen, G. S., Fuel flexibility study of an integrated 25 kW SOFC reformer system. J. Power Sources 2005, 144, 67. 
Table 1: Comparison of a number of recent SOFC exergy studies.

\begin{tabular}{ccccccc}
\hline \multirow{2}{*}{ Features } & \multicolumn{7}{c}{ Contributions } \\
\cline { 2 - 7 } & {$[18]$} & {$[19]$} & {$[21]$} & {$[23-25]$} & {$[26-27]$} & This work \\
\hline I & - & $*$ & $*$ & $*$ & $*$ & $*$ \\
II & - & $*$ & $*$ & - & - & - \\
III & - & $*$ & - & - & $*$ & $*$ \\
IV & - & - & - & - & $*$ & $*$ \\
V & $*$ & $*$ & - & - & - & $*$ \\
\hline
\end{tabular}

Notations: Considered (*), Not considered (-)

I. SOFC exergy evaluation at system level.

II. Exergy evaluation for varying flowsheets.

III. Sensitive analysis of SOFC system based on exergy evaluation.

IV. SOFC system exergy analysis while using detailed stack model in BoP.

V. Operational proposal for thermal management counting the system and stack levels performances metrics.

7

8

9

10

11

12

13

14

15

16

17

18

19

20

21

22

23 


\begin{tabular}{|c|c|c|}
\hline System operating parameters & \multicolumn{2}{|l|}{ Values } \\
\hline Fresh fuel composition, molar & \multicolumn{2}{|c|}{$85 \% \mathrm{CH}_{4}+13 \% \mathrm{~N}_{2}+1.5 \% \mathrm{H}_{2} \mathrm{O}+0.5 \% \mathrm{C}_{2+}$} \\
\hline Fuel flow rate, $\mathrm{mol} / \mathrm{s}$ & \multicolumn{2}{|c|}{$3.3 \times 10^{-5}$} \\
\hline Fuel inlet temperature, $\mathrm{K}$ & \multicolumn{2}{|l|}{1073} \\
\hline Cell operating Voltage, V & \multicolumn{2}{|l|}{0.8} \\
\hline Stack operating Voltage, $\mathrm{V}$ & \multicolumn{2}{|l|}{3.2} \\
\hline Operating pressure, bar & \multicolumn{2}{|l|}{1.0} \\
\hline Air inlet temperature, $\mathrm{K}$ & \multicolumn{2}{|l|}{1073} \\
\hline Air to fuel flow rate ratio & \multicolumn{2}{|l|}{10} \\
\hline Anode recycling ratio & \multicolumn{2}{|l|}{0.5} \\
\hline Pre-reformer temperature, $\mathrm{K}$ & \multicolumn{2}{|l|}{1073} \\
\hline Fuel cell stack specification & Cathode & Anode \\
\hline Catalyst thickness, $\mathrm{m}$ & $2.5 \times 10^{-4}$ & $3.0 \times 10^{-5}$ \\
\hline Porosity & 0.4 & 0.4 \\
\hline Anodic charge transfer coefficient & 2.0 & 1.4 \\
\hline Cathodic charge transfer coefficient & 1.0 & 0.6 \\
\hline Number of cells within stack & & \\
\hline Cell dimensions, $\mathrm{m}$ & & \\
\hline Cell flow pattern & Co-fl & fuel \\
\hline Channel height, $\mathrm{m}$ & & \\
\hline Electrolyte thickness, $\mathrm{m}$ & & \\
\hline
\end{tabular}

7 
Table 3: Variation of system and stack metrics with air flowrate

\begin{tabular}{|c|c|c|c|c|c|c|}
\hline $\begin{array}{c}\dot{m}^{\text {air }} / \dot{m}_{(-)}^{\text {air }} \\
(-)\end{array}$ & $\begin{array}{c}\overline{\bar{T}} \\
(\mathbf{K})\end{array}$ & $\begin{array}{c}\Delta \mathbf{T}_{x} \\
(\mathbf{K} / \mathbf{m m})\end{array}$ & $\begin{array}{c}\eta_{\text {total }}^{\text {ex }} \\
(\%)\end{array}$ & $\begin{array}{l}\eta_{\mathrm{el}}^{\mathrm{ex}} \\
(\%)\end{array}$ & $\begin{array}{l}\eta_{\text {th }}^{\text {ex }} \\
(\%)\end{array}$ & $\begin{array}{l}\mu_{\mathrm{ir}}^{\mathrm{ex}} \\
(\%)\end{array}$ \\
\hline 0.5 & 1269.6 & 1.93 & 63.3 & 55.7 & 7.6 & 30.4 \\
\hline $\begin{array}{l}1.0(\mathrm{BC}) \\
1.5\end{array}$ & $\begin{array}{l}1215.8 \\
1181.3\end{array}$ & $\begin{array}{l}1.32 \\
0.84\end{array}$ & $\begin{array}{l}59.2 \\
54.6\end{array}$ & $\begin{array}{l}53.7 \\
50.9\end{array}$ & $\begin{array}{l}5.5 \\
3.7\end{array}$ & $\begin{array}{l}36.1 \\
41.4\end{array}$ \\
\hline 2.0 & 1165.5 & 0.60 & 51.3 & 48.5 & 2.8 & 47.3 \\
\hline
\end{tabular}

8

Table 4: Simulation results for the system and stack behavior deploying various oxygen concentrations in fresh air.

\begin{tabular}{lcccccc}
\hline $\mathbf{y}_{\mathbf{o}_{2}}$ & $\begin{array}{c}\mathbf{T} \\
(-)\end{array}$ & $\begin{array}{c}\Delta \mathbf{T}_{\mathbf{x}} \\
(\mathbf{K} / \mathbf{m m})\end{array}$ & $\begin{array}{c}\boldsymbol{\eta}_{\text {total }}^{\text {ex }} \\
(\mathbf{\%})\end{array}$ & $\begin{array}{c}\boldsymbol{\eta}_{\text {el }}^{\text {ex }} \\
(\mathbf{\%})\end{array}$ & $\begin{array}{c}\boldsymbol{\eta}_{\text {th }}^{\text {ex }} \\
(\mathbf{\%})\end{array}$ & $\begin{array}{c}\boldsymbol{\mu}_{\mathbf{i r}}^{\text {ex }} \\
(\mathbf{\%})\end{array}$ \\
\hline $0.21(\mathrm{BC})$ & 1215.8 & 1.32 & 59.2 & 53.7 & 5.5 & 36.1 \\
0.25 & 1218.4 & 1.33 & 59.6 & 54.5 & 5.1 & 35.7 \\
0.30 & 1219.6 & 1.34 & 60.0 & 55.3 & 4.7 & 35.4 \\
0.35 & 1220.1 & 1.35 & 60.4 & 55.9 & 4.6 & 34.9 \\
0.40 & 1221.5 & 1.36 & 60.9 & 56.4 & 4.5 & 34.6 \\
\hline
\end{tabular}


Table 5: Simulation results for the system thermal behaviour against ARR.

\begin{tabular}{|c|c|c|c|c|c|c|}
\hline $\begin{array}{c}\text { ARR } \\
(-)\end{array}$ & $\begin{array}{c}\overline{\mathbf{T}} \\
(\mathbf{K})\end{array}$ & $\begin{array}{c}\Delta \mathbf{T}_{\mathbf{x}} \\
(\mathbf{K} / \mathbf{m m})\end{array}$ & $\begin{array}{c}\eta_{\text {total }}^{\text {ex }} \\
(\%)\end{array}$ & $\begin{array}{l}\eta_{\text {el }}^{\text {ex }} \\
(\%)\end{array}$ & $\begin{array}{l}\eta_{\text {th }}^{\text {ex }} \\
(\%)\end{array}$ & $\begin{array}{l}\mu_{\mathrm{ir}}^{\mathrm{ex}} \\
(\%)\end{array}$ \\
\hline 0.1 & 1208.0 & 1.07 & 55.6 & 49.3 & 6.2 & 38.7 \\
\hline 0.3 & 1213.1 & 1.21 & 57.3 & 51.4 & 5.9 & 37.5 \\
\hline $0.5(\mathrm{BC})$ & 1215.8 & 1.32 & 59.2 & 53.7 & 5.5 & 36.1 \\
\hline 0.7 & 1221.1 & 1.39 & 60.0 & 54.7 & 5.3 & 35.2 \\
\hline
\end{tabular}

4

5

6

7

Table 6: Simulation results for the system thermal behaviour operating on different fuels.

\begin{tabular}{|c|c|c|c|c|c|c|}
\hline Fuel & $\begin{array}{c}\overline{\mathbf{T}} \\
(\mathbf{K})\end{array}$ & $\begin{array}{c}\Delta \mathbf{T}_{\boldsymbol{x}} \\
(\mathrm{K} / \\
\mathbf{m m})\end{array}$ & $\begin{array}{l}\eta_{\text {total }}^{\text {ex }} \\
(\%)\end{array}$ & $\begin{array}{l}\eta_{\mathrm{el}}^{\mathrm{ex}} \\
(\%)\end{array}$ & $\begin{array}{l}\eta_{\text {th }}^{\text {ex }} \\
(\%)\end{array}$ & $\begin{array}{l}\mu_{\mathrm{ir}}^{\mathrm{ex}} \\
(\%)\end{array}$ \\
\hline $\mathrm{BC}$ & 1215.8 & 1.32 & 59.2 & 53.7 & 5.5 & 36.1 \\
\hline Designed fuel (I) & 1207.0 & 1.25 & 52.0 & 42.9 & 10.1 & 38.8 \\
\hline Designed fuel (II) & 1201.0 & 1.17 & 47.2 & 30.8 & 16.5 & 40.5 \\
\hline Syngas & 1194.5 & 1.06 & 44.0 & 23.8 & 20.2 & 41.3 \\
\hline Fuel & \multicolumn{4}{|c|}{ Composition } & \multicolumn{2}{|c|}{ Flowrate $(\mathrm{mol} / \mathrm{s})$} \\
\hline $\mathrm{BC}$ & \multicolumn{5}{|c|}{$\mathrm{CH}_{4} 85 \%, \mathrm{~N}_{2} 13 \% \mathrm{H}_{2} \mathrm{O} 1.5 \%, \mathrm{C}_{2+} 0.5 \%$} & $3.3 \times 10^{-5}$ \\
\hline Syngas $^{44}$ & \multicolumn{5}{|c|}{$36 \% \mathrm{H}_{2}+46 \% \mathrm{CO}+18 \% \mathrm{CO}_{2}$} & $1.1 \times 10^{-4}$ \\
\hline Designed fuel (I) & \multicolumn{4}{|c|}{$70 \%$ Basis fuel $+30 \%$ Syngas } & \multicolumn{2}{|c|}{$5.6 \times 10^{-5}$} \\
\hline Designed fuel (II) & \multicolumn{4}{|c|}{$30 \%$ Basis fuel $+70 \%$ Syngas } & \multicolumn{2}{|c|}{$8.7 \times 10^{-5}$} \\
\hline
\end{tabular}

10 


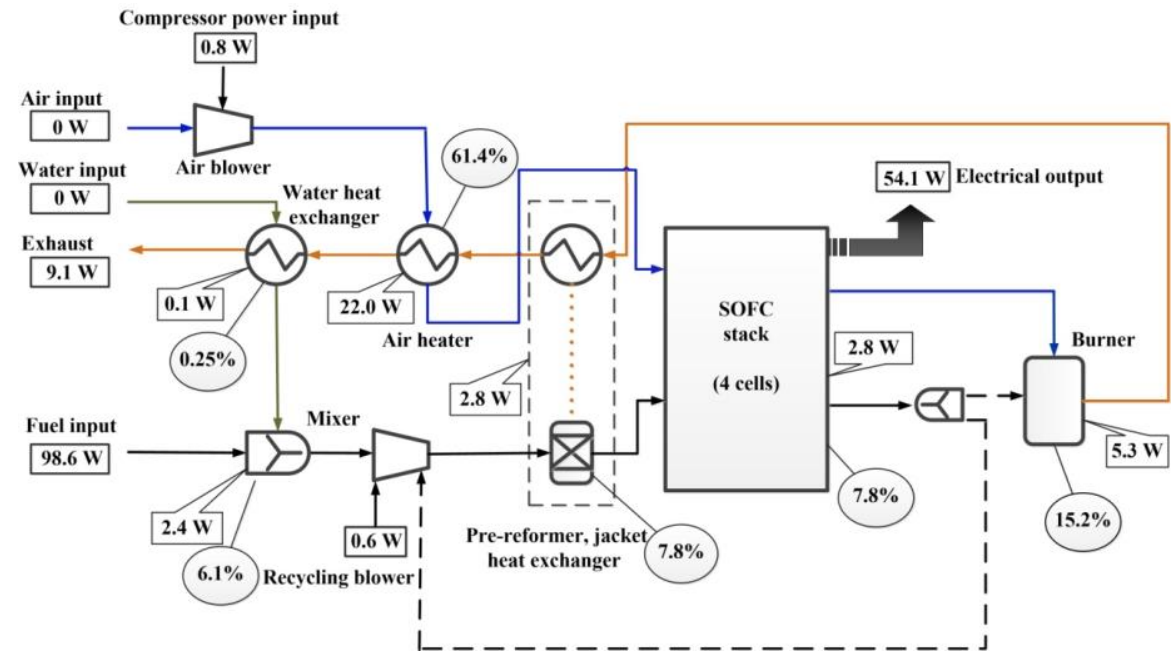

Figure 1: Process layout for a SOFC system showing the indicative exergy results for the basis case simulation including the sub-process exergy loss (rectangular boxes with arrow), exergy loss to the input exergy into the system ratio (oval boxes), and system input and output exergies (rectangular boxes without arrow).

\section{Energy}

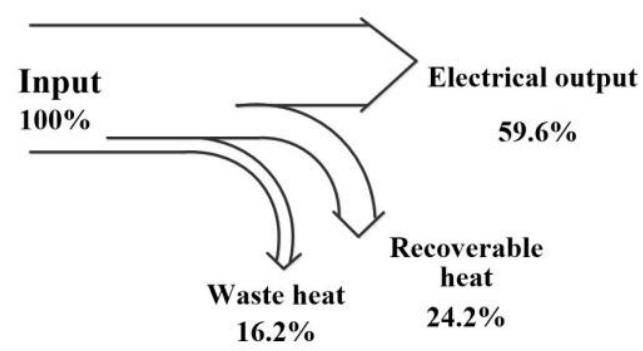

\section{Exergy}

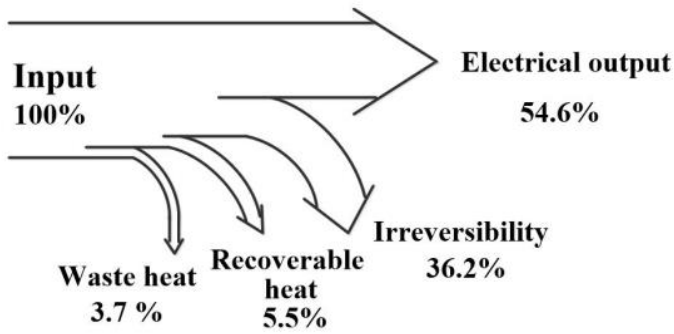

Figure 2: The plant analysis based on energy and exergy principles. 


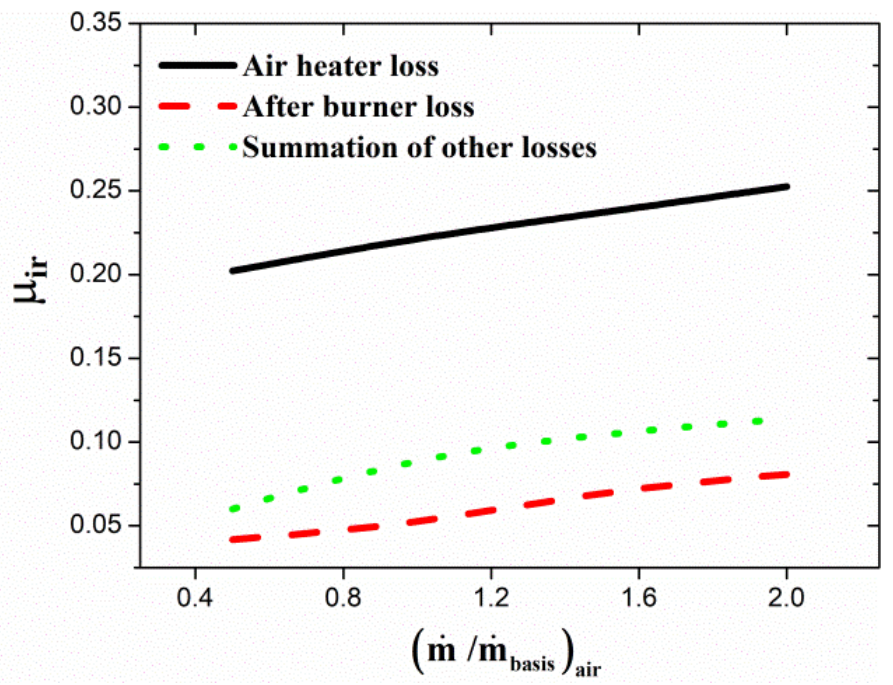

Figure 3: Ratio of the exergy losses to the total exergy input for different air flow rates.

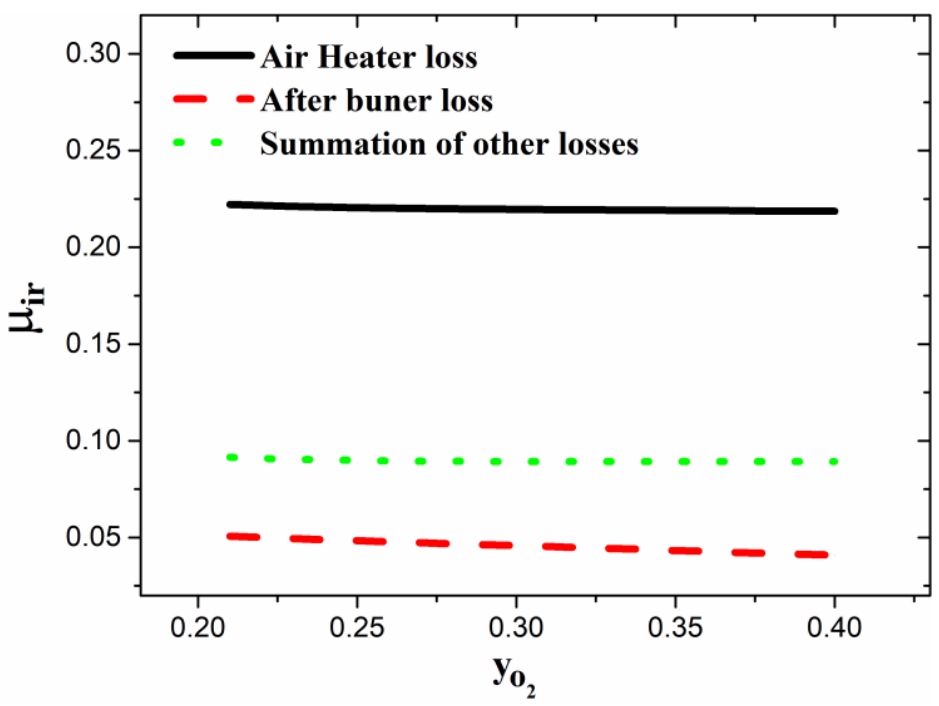

Figure 4: Ratio of the exergy losses to the total exergy input for different oxygen concentrations used in cathode gas. 


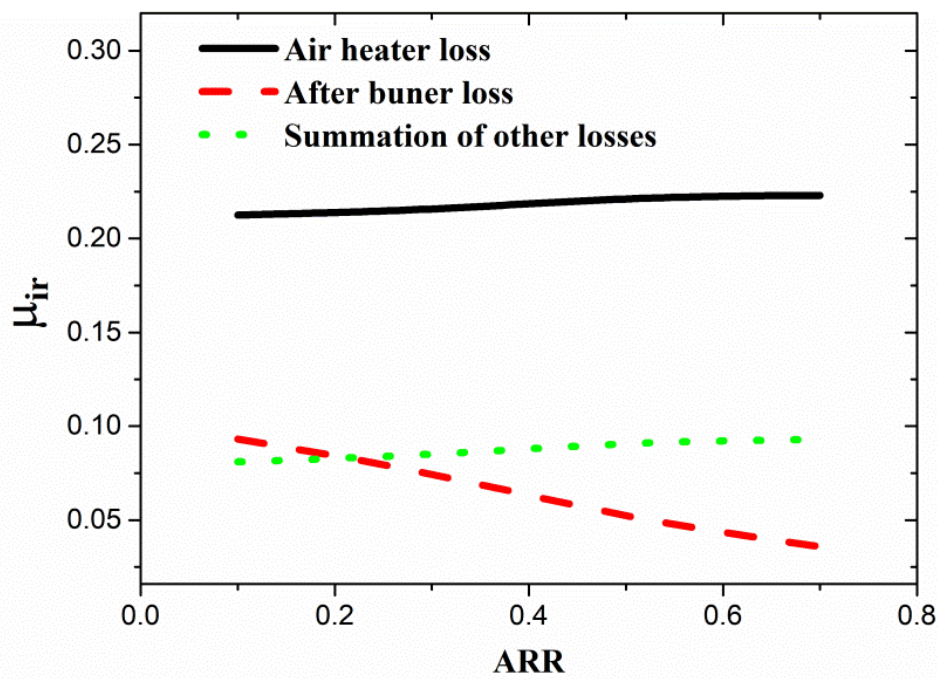

Figure 5: Effect of ARR on BoP units' exergy loss ratio.

6

7

8

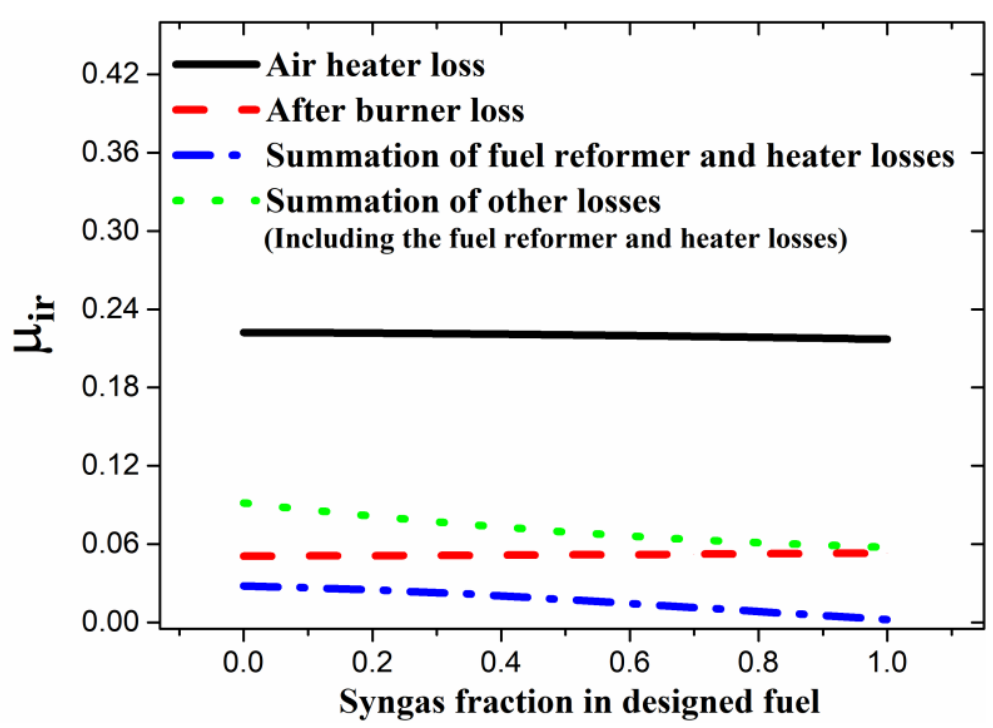

Figure 6: Ratio of the exergy loss to the total exergy input for different fuel compositions used in the system. 


\section{9}

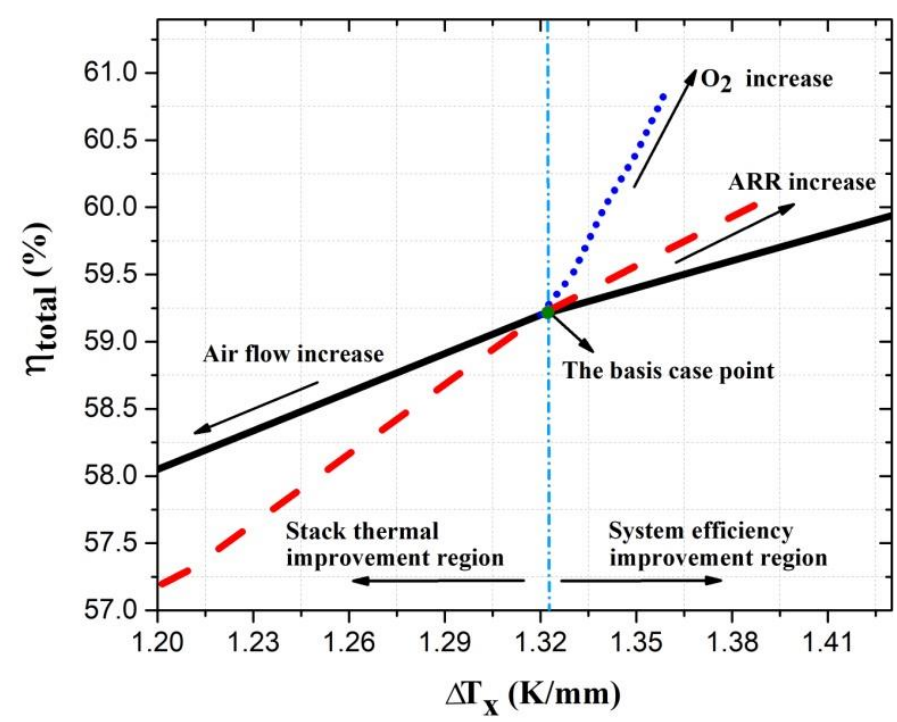

Figure 7: System efficiency against the stack temperature gradient for individual operational strategies.

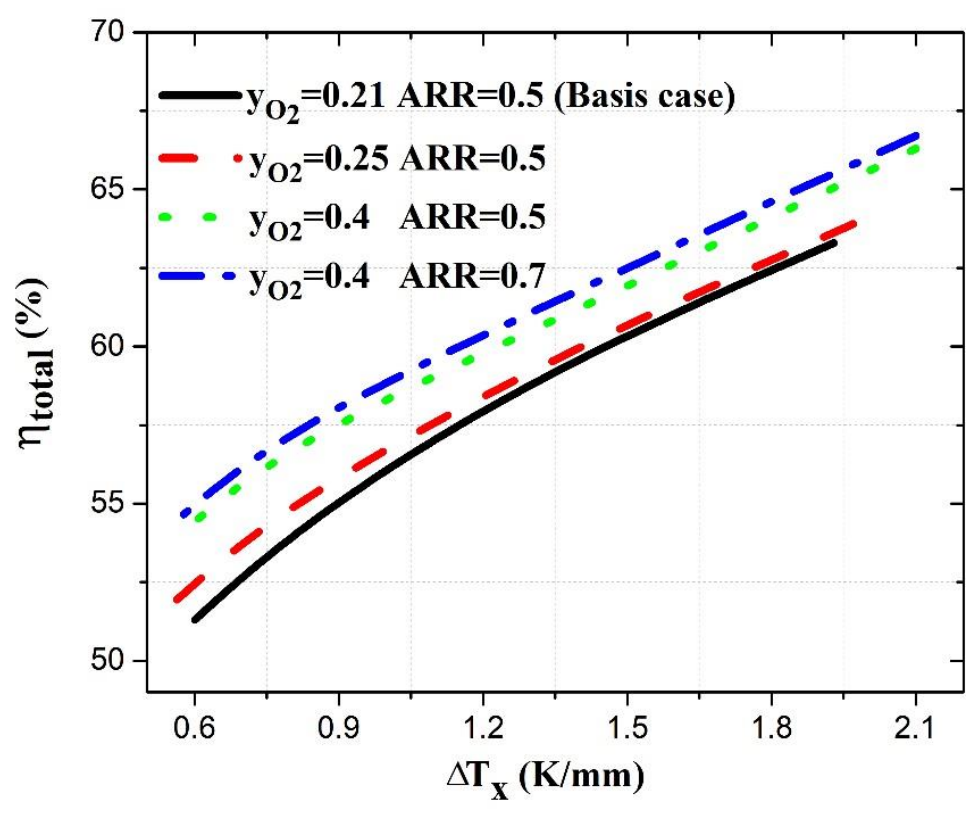

Figure 8: System exergy-based efficiency again the stack thermal gradient for coolant air flowrates varying from 0.5 to 2 times of the basis air flow, combined with ARR and yo2 impacts. 


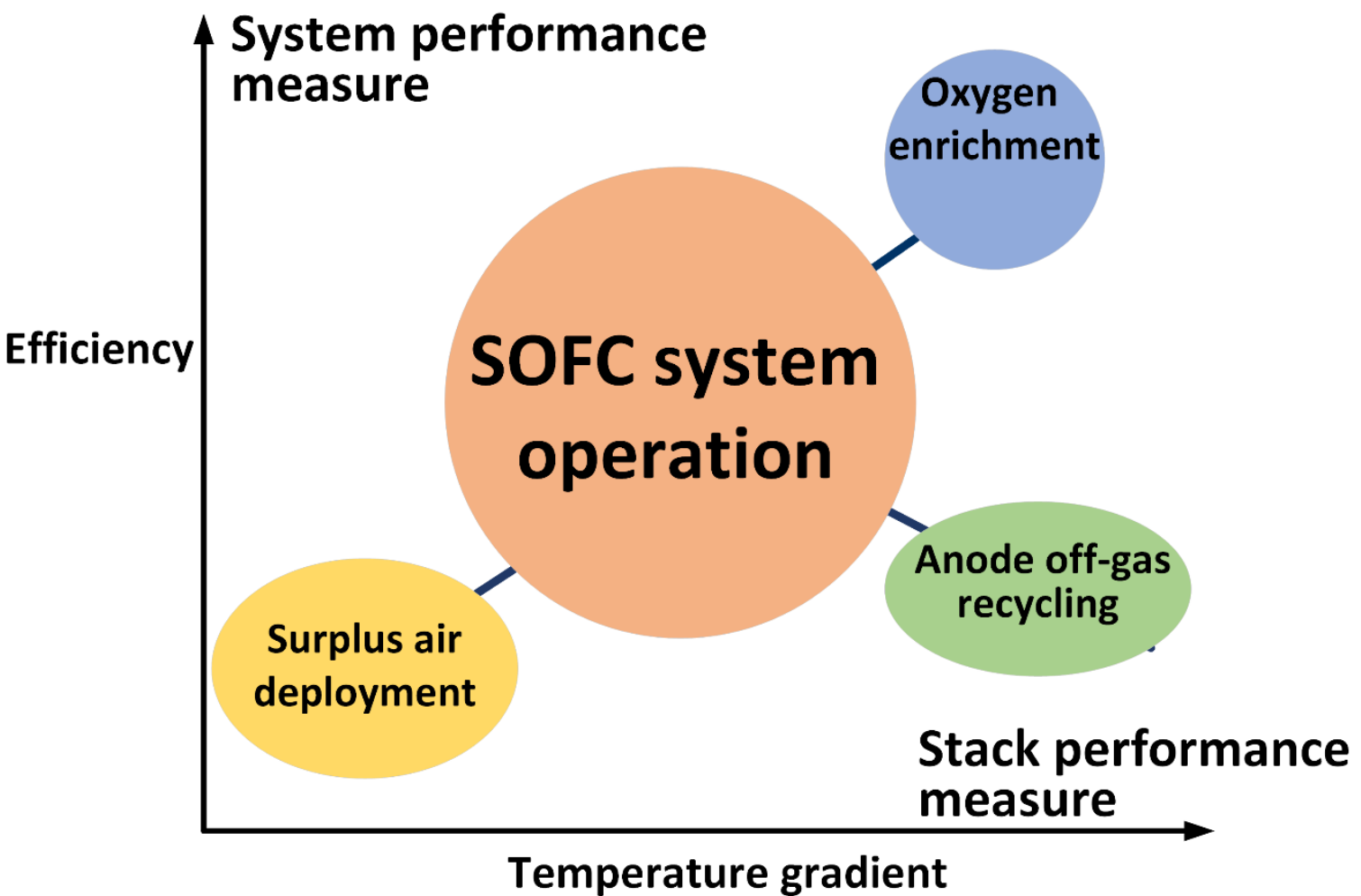

